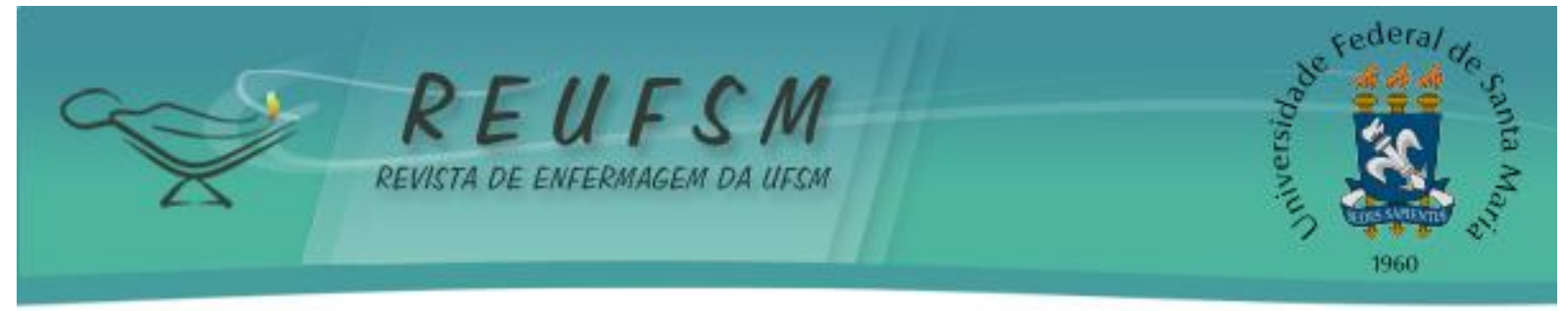

ARTIGO ORIGINAL

\title{
CONTAÇÃO DE HISTÓRIA NA UNIDADE PEDIÁTRICA: PERCEPÇÃO DE ACOMPANHANTES DE CRIANÇAS HOSPITALIZADAS
}

\section{STORYTELLING IN THE PEDIATRIC UNIT: PERCEPTION OF PERSONS ACCOMPANYING HOSPITALIZED CHILDREN}

\section{CUENTACUENTOS EN LA UNIDAD PEDIÁTRICA: PERCEPCIÓN DE LOS ACOMPAÑANTES DE NIÑOS HOSPITALIZADOS}

\author{
Thayla Nadrielly Aparecida Nicolino ${ }^{1}$ \\ Mayara Caroline Barbieri ${ }^{2}$ \\ Mauren Teresa Grubisich Mendes Tacla ${ }^{3}$ \\ Rosângela Aparecida Pimenta Ferrari ${ }^{4}$
}

Doi: $10.5902 / 2179769213204$

RESUMO: Objetivo: apreender a percepção dos acompanhantes de crianças sobre a contação de histórias durante a hospitalização. Método: pesquisa qualitativa com oito acompanhantes de crianças internadas na unidade pediátrica. Os dados foram coletados por meio de entrevista semiestruturada e analisados pelo método de análise temática. Resultados: emergiram duas categorias: $A$ hora do conto: diversão dentro do hospital $e$ Uma viagem ao mundo da fantasia: onde a dor não tem vez. Considerações finais: a contação de histórias no ambiente hospitalar é uma estratégia que deve ser utilizada para a recuperação da criança, o controle da dor e diminuição de estresse e traumas decorrentes da internação tanto para a criança quanto para seu acompanhante.

Descritores: Enfermagem pediátrica; Hospitalização; Criança; Manejo da dor.

ABSTRACT: Aim: to raise awareness about the perception that people accompanying children have on storytelling during hospitalization. Method: qualitative research with eight people accompanying children in the pediatric unit. Data were collected through semi-structured interviews and analyzed using thematic analysis. Results: two categories emerged: Story time: fun in the hospital and A journey to the world of fantasy: no room for pain. Final Considerations: telling stories in the hospital setting is a strategy that should be used for the child's recovery, control of pain and reduction of stress and trauma resulting from hospitalization for both the child and accompanying persons.

Descriptors: Pediatric nursing; Hospitalization; Child; Pain management.

RESUMEN: Objetivo: captar la percepción de los acompañantes de niños sobre el cuentacuentos durante la hospitalización. Método: investigación cualitativa con ocho acompañantes de niños ingresados en unidad de pediatria. Los datos fueron recolectados mediante entrevistas semi-estructuradas y analizados por el método de análisis temático. Resultados: surgieron dos categorías: La hora del cuento: diversión dentro del hospital y Un viaje al mundo de la fantasía: donde el dolor no tiene lugar. Consideraciones finales: la narración de cuentos en el ámbito hospitalario es una estrategia que se debe utilizar

\footnotetext{
1 Enfermeira, Pós-graduanda em Controle de Infecções relacionadas a Assistência a Saúde, Universidade Estadual de Londrina. Londrina, Paraná, Brasil. E-mail: nadry1@hotmail.com

2 Enfermeira, Mestranda pelo Programa de Pós-Graduação em Enfermagem, Universidade Federal de São Carlos. São Carlos, São Paulo, Brasil. E-mail: may_barbieri@hotmail.com

3 Enfermeira, Doutora, Professor Adjunto do Departamento de Enfermagem, Centro de Ciências da Saúde, Universidade Estadual de Londrina. Londrina, Paraná, Brasil. E-mail: maurentacla@gmail.com.br

${ }^{4}$ Enfermeira, Doutora, Professor Adjunto do Departamento de Enfermagem, Centro de Ciências da Saúde, Universidade Estadual de Londrina. Londrina, Paraná, Brasil. E-mail: ropimentaferrari@uel.br
} 


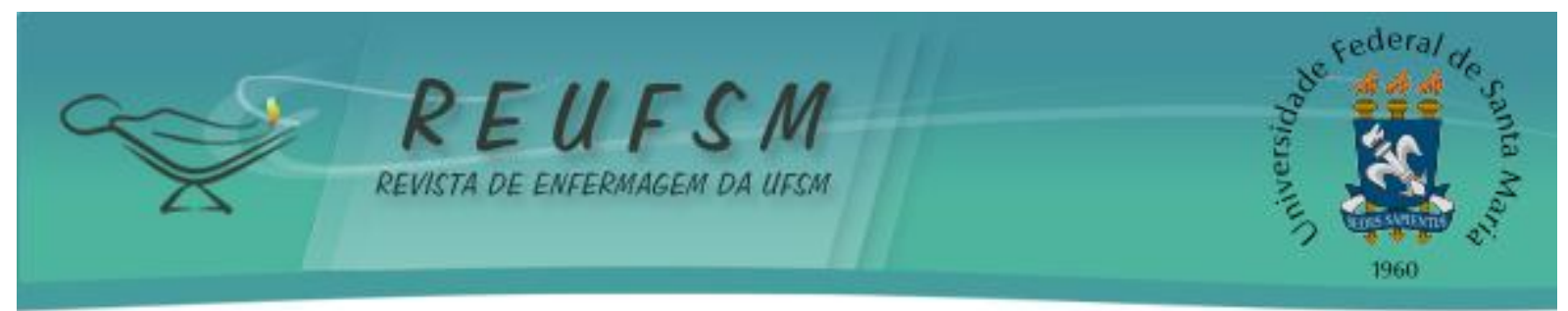

para la recuperación, el control del dolor del niño y la reducción del estrés y los traumas resultantes de la hospitalización tanto para el niño como para su acompañante.

Descriptores: Enfermería pediátrica; Hospitalización; Niño; Manejo del dolor.

\section{INTRODUÇÃO}

O processo de hospitalização infantil é marcante, pois neste momento a criança fica frágil e impossibilitada de realizar suas atividades cotidianas, alterando sua rotina como brincar e ir à escola. ${ }^{1}$

O hospital para a criança é um ambiente diferente, desconhecido e, na maioria das vezes, assustador, pois a criança se afasta da sua família, da sua casa, dos seus amigos, da escola, dos seus objetos pessoais, perdendo grande parte dos seus referenciais, além de ser submetida a processos dolorosos e desagradáveis sobre a qual não terá escolha. ${ }^{2}$ A equipe de saúde deve utilizar estratégias para minimizar o sofrimento do paciente e família que vivencia a hospitalização, buscando um cuidado integral. ${ }^{3}$

A Resolução $n^{\circ}$ 41/95, do Conselho Nacional dos Direitos da Criança e do Adolescente, regulamenta os Direitos da Criança e do Adolescente Hospitalizados e, em seu artigo 9, destaca "o direito das crianças a desfrutarem de recreações, programas de educação para a saúde e acompanhamento do currículo escolar durante a hospitalização". ${ }^{4}$

Uma das estratégias para minimizar o sofrimento no ambiente hospitalar é o desenvolvimento de atividades lúdicas. Assim, a criança pode, por alguns momentos, se aproximar da sua realidade cotidiana. O brincar é essencial para o desenvolvimento da criança e está presente em todas as fases da vida favorecendo além da diversão, a expressão de sentimentos e emoções pelas quais o indivíduo passa. ${ }^{5}$

Algumas instituições hospitalares estão tornando o lúdico mais acessível aos pacientes internados, trazendo esta atividade como uma ferramenta de trabalho diário, apresentando-a como facilitadora da assistência. ${ }^{6} \mathrm{O}$ brincar no ambiente hospitalar deve ser adaptado de acordo com a idade da criança e com as suas limitações, como exemplo membros imobilizados ou incapacidade de permanecer em pé. ${ }^{7-8}$ Entre as inúmeras atividades que podem ser realizadas e que não oferece limitação para a criança, mas sim, total disponibilidade do executar é a contação de história. Esta ação agrada a todos, não faz distinção de circunstâncias de vida, em especial durante a internação hospitalar. Contar uma história vai além de diversão e estímulo da imaginação, quando bem contada ela é capaz de educar, instruir, desenvolver o raciocínio, auxiliando na compreensão de situações desagradáveis e ajudando a resolver conflitos. ${ }^{8}$

Esta atividade possui valor terapêutico, pois ao contar histórias além de melhorar a qualidade de vida da criança no período de hospitalização, também contribui amenizando as repercussões físicas e psicológicas do adoecimento e reduz impactos negativos da quebra do contexto sócio familiar e dos procedimentos utilizados no tratamento. ${ }^{5}$ Assim, o conhecimento da contribuição na estratégia de contar histórias é essencial para que forneça subsídios para o melhor entendimento das crianças e acompanhantes pelos profissionais da saúde, refletindo assim na qualidade da assistência a esses indivíduos.

Feitas essas considerações, a questão que norteou a pesquisa foi: que efeitos a contação de histórias pode ter sobre as crianças hospitalizadas em uma unidade pediátrica, na perspectiva dos acompanhantes?

Sendo esta uma atividade considerada terapêutica e utilizada em unidades de internação, em especial nas unidades pediátricas, o presente estudo teve como objetivo apreender a percepção dos acompanhantes de crianças sobre a contação de histórias durante a hospitalização. 


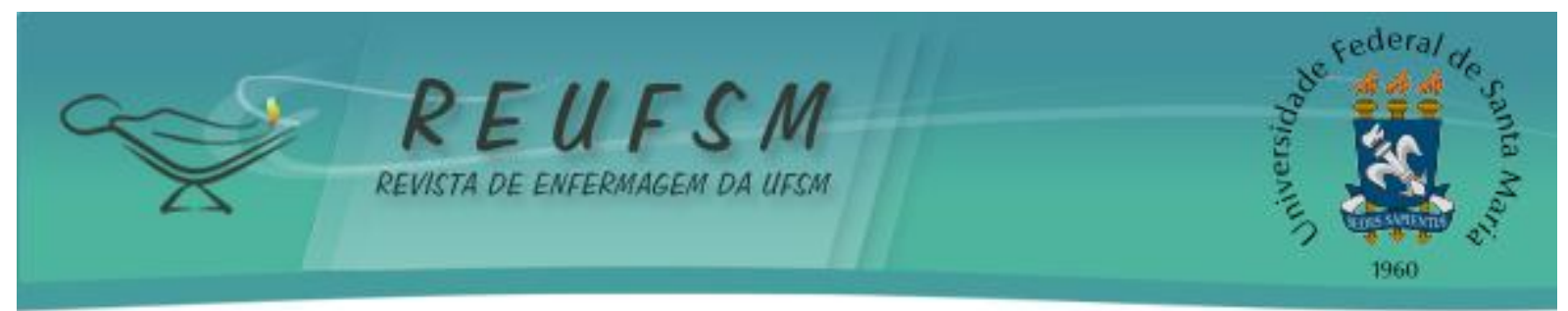

MÉTODO

Trata-se de um estudo de abordagem qualitativa, realizado na unidade pediátrica de um hospital-escola público de grande porte em Londrina-Paraná (PR), que atende pacientes de zero a 12 anos incompletos. Possui 34 leitos e uma equipe multiprofissional, alunos de graduação e pós-graduação nas áreas de enfermagem, medicina, fisioterapia, farmácia, psicologia e serviço social. Também conta com a atuação de um grupo profissional de teatro, o "Plantão Sorriso" e com o grupo acadêmico "Sensibilizarte" composto por alunos dos cursos de Enfermagem, Fisioterapia, Psicologia, Medicina e Farmácia, criado no inicio de 2007 e, desde então, atende pacientes adultos e crianças internados no hospital realizando atividades lúdicas em quatro frentes: os palhaços, a contação de histórias, o artesanato e a música. ${ }^{9}$

$\mathrm{Na}$ unidade pediátrica o "Sensibilizarte" desenvolve a contação de história nas terças-feiras à tarde, com duração média de uma hora, sendo que a coleta de dados da presente pesquisa foi iniciada após a sua realização. As histórias são selecionadas anteriormente, porém as crianças apresentam a possibilidade de solicitarem outras histórias e as sessões são realizadas em grupos, de acordo com a disposição das crianças nas enfermarias. 0 local da realização da contação de histórias se justifica devido ao uso de dispositivos por alguns pacientes tais como bombas de infusão, ventiladores mecânicos etc. A equipe de saúde multidisciplinar da unidade apenas observa.

Os oito participantes, que eram acompanhantes de crianças entre seis a 12 anos internadas no período de agosto a setembro de 2010, tiveram suas entrevistas gravadas após aceite e assinatura do Termo de Consentimento Livre e Esclarecido (TCLE). Os participantes foram escolhidos de forma aleatória. Utilizou-se um instrumento com questões semiestruturadas baseadas em perguntas norteadoras quanto à percepção do acompanhante sobre a contação de história dentro do ambiente hospitalar e se ela trazia algum benefício ou não para criança e/ou ajudava no controle da sua dor.

Os dados foram analisados após transcrição das entrevistas utilizando-se o método de análise temática seguindo as seguintes etapas: a exploração textual por meio da leitura e significação; leitura flutuante, momento em que o pesquisador tem um contato direto e intenso com o material de campo, deixando-se aprofundar no seu conteúdo; delineamento dos temas; análise temática focalizando os argumentos utilizados; demarcação das categorias e, a fase interpretativa, que relaciona ideias explícitas e implícitas expressada pelos pesquisados. ${ }^{10}$

Os procedimentos éticos deste estudo foram seguidos, de acordo com a Resolução $466 / 12$ do Ministério da Saúde. ${ }^{11}$ A pesquisa foi aprovada pelo Comitê de Ética em Pesquisa envolvendo seres humanos da Universidade Estadual de Londrina, sob parecer $n^{\circ} 079 / 10$ e Certificado de Apresentação para Apreciação Ética $n^{\circ}$ 0076.0.268.000-10. Para manter o anonimato dos participantes utilizou-se a sigla Ac. (acompanhante) seguida da ordem numérica das entrevistas.

\section{RESULTADOS E DISCUSSÃO}

A análise das entrevistas permitiu a identificação de duas categorias: A hora do conto: diversão dentro do hospital e Uma viagem ao mundo da fantasia: onde a dor não tem vez.

\section{A hora do conto: diversão dentro do hospital}

Esta categoria trata do quanto a contação de histórias pode contribuir para a recuperação da criança em um ambiente hospitalar e aborda os benefícios alcançados após a 


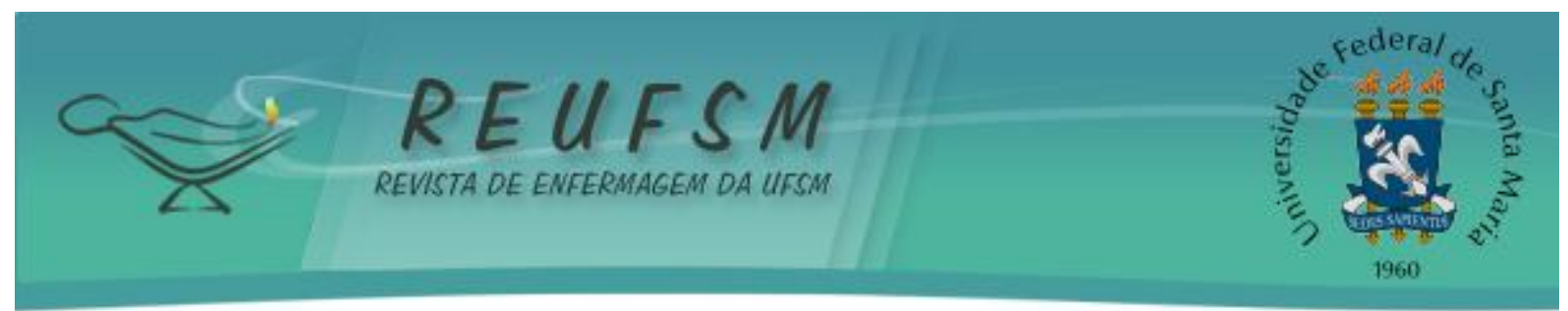

execução desta atividade terapêutica. Nos depoimentos dos participantes é possível identificar que os mesmos valorizam a prática de contar histórias, pois consideram que ela promove um momento de diversão para a criança durante a internação. Revelam que esta ação distrai, diverte e, principalmente, alegra as crianças internadas, conforme discursos a seguir:

Eu acho que ajuda na melhora da criança. Ela se anima com a história e participa. (Ac. 2)

Acho que desliga um pouco daqui e assim fica mais feliz! (Ac. 3)

É diversão! [...] Mais animação, mais possibilidade de melhoras rápidas e alegria! (Ac. 5)

Eu acho bom... As crianças se divertem, elas gostam. Eu acho bem legal esse trabalho de vocês com eles. Para entreter um pouco as crianças e entreter até a gente [...]. Distrai né! Esquecem um pouco o que estão passando. (Ac. 6)

Olha, ao meu ver achei interessante. Que nem o meu neto, ele chega contando: "Olha vó, hoje eu não chorei muito porque tinha os palhaços; porque a tia contou histórias pra mim [...]" Ele já tinha comentado pra mim. Eu acho muito interessante porque a gente que é mãe, que é avó, a gente sente o que eles passam e isso distrai a cabecinha deles. Hoje ele estava bem agitado com saudade da mãe dele; agora, depois de ouvir a história ele está bem melhor. Eu achei interessante e ele adora [...]! O benefício maior que traz mesmo é a alegria deles. Eles ficam bem mais contentes! Eles se distraem. (Ac. 8)

O aumento da alegria e da diversão nas crianças hospitalizadas, observado na presente pesquisa, após a contação de histórias, é também relatado em outra pesquisa em que se observou que dez das 15 crianças apresentaram melhora no seu estado emocional, acalmando-se quando estavam agitadas ou chorando. ${ }^{12}$

Estudo realizado em Minas Gerais, as atividades lúdicas, de forma geral, foram consideradas positivas para a recuperação da criança hospitalizada, pois $100 \%$ dos pais mencionaram melhora no humor dos seus filhos e $93 \%$ tiveram aumento da disposição. ${ }^{5}$

A hospitalização é uma situação de estresse para a criança, não somente pelo tratamento, mas também por se encontrar em um ambiente restritivo e diferente do seu universo, assim as atividades lúdicas mostraram-se como um benefício físico e emocional. ${ }^{12}$

Além dos discursos dos acompanhantes abordarem que a contação de histórias aflora sentimentos de alegria nas crianças percebe-se também a valorização desta ação no aumento do conhecimento, raciocínio e concentração das crianças, pois enquanto ficam internados deixam de frequentar a escola.

Eles entendem melhor a história. (Ac. 1)

Eu acho que trabalha bastante a mente [...] eu acho que ajuda a amenizar no psicológico! Você vê que ele se distrai dessas partes chatas de estar internado e fica concentrado no que você fala para eles. E eu acho que isso ajuda! (Ac. 3) 


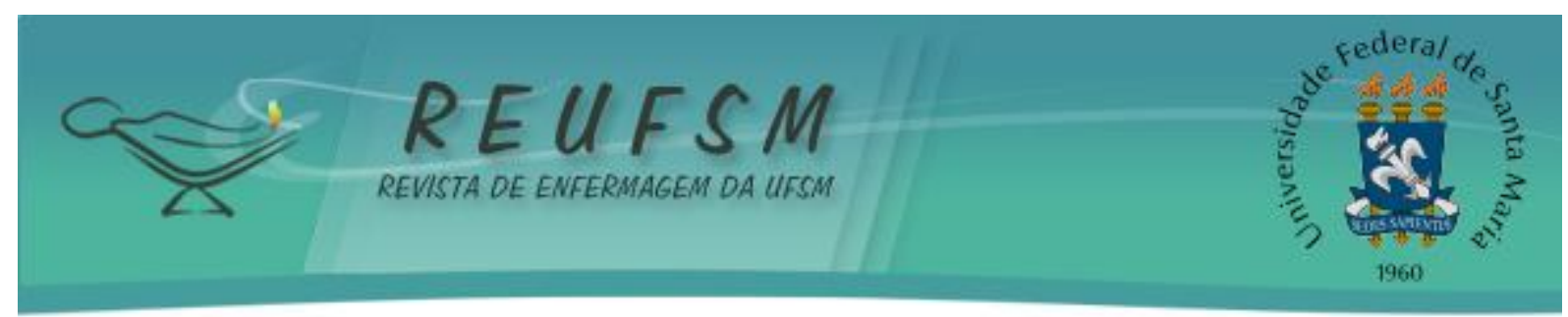

Tem criança que está até um mês sem estudar [...] o meu menino mesmo faz 10 dias que está sem ir pra escola e isso ajuda. Eu gosto, acho que chama atenção. (Ac. 4)

Desenvolvem o estudo mesmo [...] desenvolvem a cultura, ouvem histórias diferentes [...] ficam tempo sem ir pra escola e quando voltam contam para os colegas as histórias ouvidas. (Ac. 6)

Eu acho que grava, fica na cabecinha deles conforme o tempo vai passando. (Ac. 7)

A contação de histórias age na formação da criança em várias áreas. Ela contribui no seu desenvolvimento intelectual, pois desperta o interesse pela leitura e estimula a imaginação por meio de imagens de cenários, personagens e ações narradas em cada história. Além disso, provoca nas crianças o desenvolvimento de operações mentais na construção dos significados das palavras ouvidas, que aliadas ao contexto da narrativa, possam enriquecer o seu vocabulário. ${ }^{2}$

A história serve de alimento para a alma, ela desperta a curiosidade e estimula a busca por explicações. Ela vive profundamente tudo que as narrativas provocam. ${ }^{2} 0$ contar histórias implica também em desenvolver todo potencial crítico da criança, pois a criança é levada a pensar, questionar e duvidar, estimulando o censo crítico. ${ }^{8}$

\section{Uma viagem ao mundo da fantasia: onde a dor não tem vez}

Esta categoria aborda a contação de história como um momento em que a criança esquece em parte o seu cotidiano de hospitalização tendo uma maior interação com a brincadeira e minimizando a sensação dolorosa. Pôde-se apreender nos discursos dos acompanhantes o quanto essa atividade favoreceu a redução da dor.

Ajuda porque quando a criança está ouvindo história ela se concentra na história e ela esquece a dor naquele momento e isso é bom [...] (Ac. 5)

Ajuda a distrair. Ela entra na história e até esquece da hospitalização, dor [...] É uma coisa diferente. (Ac. 6)

Ela esquece a dor naquele momento. (Ac. 7)

[...] a criança fica mais calma. As histórias mexem com o lado bom das coisas, com o psicológico dele, porque ele está cansado, estressado, $e$ isso ajuda muito. Eles entrarem no mundo da historinha, imaginar aquilo que está passando na história. $A$ história ajuda muito ele a esquecer a doença e o que esse está passando e o que está sentindo. Ele se envolve muito. (Ac. 8)

Pesquisa realizada na cidade de Londrina-PR mostrou que a maior parte dos acompanhantes de crianças no período pós-operatório utilizou a distração como forma de aliviar a dor de seus filhos. As autoras salientaram que a dor não é eliminada com esta técnica, porém se torna mais tolerável quando é substituída por outro pensamento, proporcionando a criança um senso de controle sobre a dor. ${ }^{13}$ 


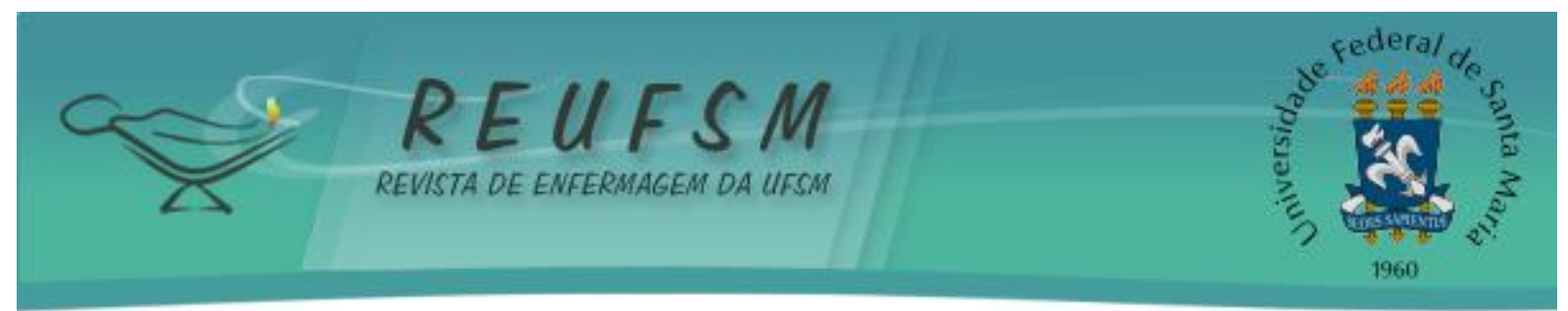

O brincar é uma das formas que a criança tem para se comunicar com o mundo que a rodeia, e a contação de histórias é um recurso fundamental na socialização e desenvolvimento saudável de todas as crianças. Portanto, ameniza situações estressantes, diminui a ansiedade aumentando a demonstração de alegria e bom humor e contribui para melhor integração dos pacientes e familiares com os profissionais da saúde. ${ }^{14}$

0 relato da distração e diminuição da dor vem ao encontro com uma pesquisa realizada na Santa Casa de Misericórdia, São Paulo, em que foi avaliado a dor de 15 crianças antes da visita dos contadores de história, dessas, oito relataram dor antes da atividade lúdica e após a atuação dos contadores seis afirmaram que diminuiu, sendo que três estavam recebendo quimioterapia e estas não estavam em uso de medicações analgésicas antes e após a contação de história. ${ }^{12}$

Pesquisa realizada no Hospital da Clínicas do Triangulo Mineiro evidenciou que o desenvolvimento de atividades lúdicas, por meio da música, teatro, brincadeiras e conversas, possibilitaram a descontração e a redução de angústias que uma internação pode causar tanto nos adultos, como nas crianças e acompanhantes no ambiente hospitalar. ${ }^{6}$ Tais resultados também foram evidenciados em pesquisa realizada em Santa Catarina, que tanto as crianças como os acompanhantes que se encontraram juntamente com as crianças no momento da contação de histórias, mostraram-se receptivos compartilhando efetivamente desses momentos. ${ }^{15}$

A promoção do brincar também é apresentada como um recurso interdisciplinar, por auxiliar a interação entre os profissionais de saúde, as crianças e os acompanhantes e por ser um facilitador do modelo tradicional de intervenção durante o cuidado de crianças hospitalizadas. ${ }^{16}$ Este cuidado requer uma ausculta sensível nas relações, principalmente entre profissional da saúde e o sujeito a ser cuidado, objetivando atender o outro na sua multidimensionalidade. ${ }^{17}$

É necessário garantir, durante a internação hospitalar, que os cuidados possam ir além do físico e biológico, eles devem também envolver o psicológico, o social e o espiritual, por meio de atividades lúdicas como a contação de história. ${ }^{6}$ Essa prática pode ser executada não só por grupos especializados na unidade, mas em todos os momentos que os profissionais executarem a assistência.

\section{CONSIDERAÇÕES FINAIS}

No presente estudo pode-se apreender que a contação de história para os acompanhantes foi considerada uma ação benéfica para a criança durante a hospitalização por promover o estímulo à imaginação e alegria, além de diminuir o estresse, a tristeza e a dor dos pacientes pediátricos.

Assim, apesar desta pesquisa demonstrar diversos benefícios da contação de histórias no ambiente hospitalar, é necessário que outros estudos sejam realizados sobre a temática, visto que as vantagens desta estratégia podem ser observadas a longo prazo.

A adesão da prática de contar histórias dentro do hospital é uma ação que pode ser recomendada para ajudar na recuperação da criança, no controle da dor e, também, proporcionar uma hospitalização menos traumatizante e estressante tanto para a criança quanto para seu acompanhante. 0 enfermeiro deve estar instrumentalizado para o cuidado humanizado à criança e família, sendo a contação de histórias uma estratégia que pode ser utilizada para a aproximação e bem-estar dos pacientes e acompanhantes. 


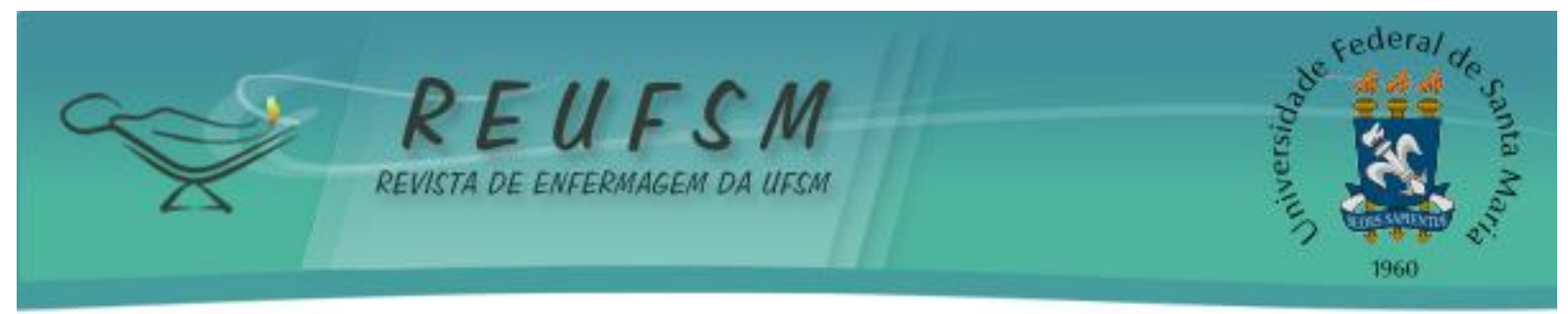

\section{REFERÊNCIAS}

1. Oliveira LDB, Gabarra LM, Marcon C, Silva JLC, Macchiaverni J. A brinquedoteca hospitalar como fator de promoção no desenvolvimento infantil: relato de experiência. Rev Bras Crescimento Desenvolv Hum [Internet]. 2009 [acesso em 2012 nov 28];19(2):306-12. Disponível em: http://www.revistas.usp.br/jhgd/article/download/19920/21997.

2. Ceribelli C, Nascimento LC, Pacífico SMR, Lima RAG. A mediação de leitura como recurso de comunicação com crianças hospitalizadas. Rev Latinoam Enferm [Internet]. 2009 [acesso em 2012 dez 19];17(1):81-7. Disponível em: http://www.scielo.br/pdf/rlae/v17n1/pt_13.pdf.

3. Vicenzi A, Schwartz E, Cecagno D, Viegas AC, Santos BP, Lima JF. Cuidado integral de enfermagem ao paciente oncológico e à família. Rev Enferm UFSM [Internet]. 2013 set-dez [acesso em 2013 dez 29];3(3):409-17. Disponível em: http://cascavel.ufsm.br/revistas/ojs2.2.2/index.php/reufsm/article/view/8816.

4. Brasil. Conselho Nacional dos Direitos da Criança e do Adolescente. Resolução $n^{\circ} 41$, de 13 de outubro de 1995. Direitos da Criança e do Adolescente Hospitalizados [Internet]. Diário Oficial da União, Brasília; 1995 set 17 [2013 dez 12]. Seção I, p.163/9-16320. Disponível em: http://www.ufrgs.br/bioetica/conanda.htm.

5. Castro DP, Andrade CUB, Luiz E, Mendes M, Barbosa D, Santos LHG. Brincar como instrumento terapêutico. Pediatria [Internet]. 2010 [acesso em 2012 out 29];32(4):246-54. Disponível em: http: //www.pediatriasaopaulo.usp.br/upload/pdf/1360.pdf.

6. Simões ALA, Maruxo HB, Yamamoto LR, Silva LC, Silva PA. Satisfação de clientes hospitalizados em relação às atividades lúdicas desenvolvidas por estudantes universitários. Rev Eletrônica Enferm [Internet]. 2010 [acesso em 2013 fev 26];12(1):10712. Disponível em: http://www.revistas.ufg.br/index.php/fen/article/view/9528/6596.

7. Collet N, Oliveira BRG, Vieira CS. Manual de enfermagem em pediatria. $2^{\mathrm{a}}$ ed. Goiânia: AB editora; 2010.

8. Torres SM, Tettamanzy ALL. Contação de histórias: resgaste da memória e estímulo à imaginação. Nau Literária [Internet]. 2008 [acesso em 2013 jan 10];04(01):1-8. Disponível em: http://www.seer.ufrgs.br/index.php/NauLiteraria/article/view/5844/3448.

9. International Federation of Medical Students Associations of Brazil. SensibilizArTe [Internet]. 2011 [acesso em 2013 set 12]. Disponível em: http://www.ifmsabrazil.org/Default.aspx?pageld=535689.

10. Bardin L. Análise de conteúdo. Lisboa: Edições 70; 2009.

11. Brasil. Ministério da Saúde. Resolução CNS n 466, de 12 de dezembro de 2012. Diretrizes e normas regulamentadoras de pesquisa envolvendo seres humanos. Brasil: Ministério da Saúde, Conselho Nacional de Saúde; 2012.

12. Mussa C, Malerbi FEK. O impacto da atividade lúdica sobre o bem-estar de crianças hospitalizadas. Psicol Teor Prát. 2008;10(2):83-93.

13. Silva LDG, Tacla MTGM, Rossetto EG. Manejo da dor pós-operatória na visão dos pais da criança hospitalizada. Esc Anna Nery Rev Enferm [Internet]. 2010 [acesso em $2013 \mathrm{fev}$ 18];14(3):519-26. Disponível em: http://www.scielo.br/pdf/ean/v14n3/v14n3a13.pdf.

14. Moraes MCAF, Buffa MJMB, Motti TFG. As atividades expressivas e recreativas em crianças com fissura labiopalatina hospitalizadas: visão dos familiares. Rev Bras Educ Espec 


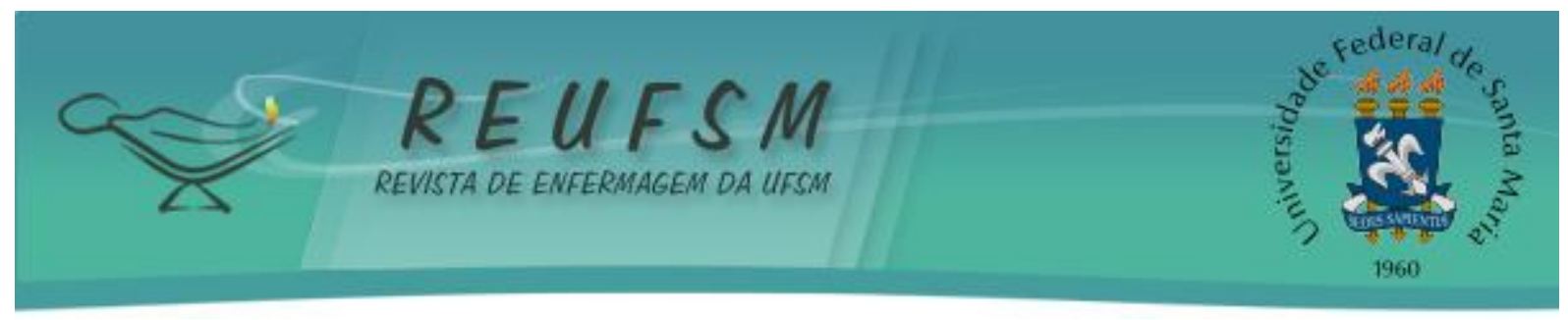

[Internet]. 2009 [acesso em 2013 jan 8];15(3):453-70. Disponível em: http: //www.scielo.br/pdf/rbee/v15n3/a09v15n3.pdf.

15. Knoche LMM. Contar, ler e brincar: a importância da contação e da leitura de histórias aliadas ao lúdico como agentes transformadores da rotina hospitalar. Rev ACB: Biblioteconomia em Santa Catarina [Internet]. 2013 [acesso em 2013 jul 23];18(1):576-98. Disponível em: http://revista.acbsc.org.br/racb/article/view/871.

16. Mitre RMA, Gomes R. A perspectiva dos profissionais de saúde sobre a promoção do brincar em hospitais. Cienc Saúde Colet [Internet]. 2007 [acesso em 2013 jan 23];12(5):1277-84. Disponível em: http://www.scielo.br/pdf/csc/v12n5/19.pdf.

17. Gelbcke FL, Reibnitz KS, Prado ML, Lima MM, Kloh D. A práxis da enfermeira e a integralidade no cuidado. Enferm em Foco. 2011;2(2):116-9.

Data de recebimento: $18 / 03 / 2014$

Data de aceite: 12/01/2015

Contato com autor responsável: Mayara Caroline Barbieri

Endereço postal: Rua Visconde de Inhaúma, 1329, CEP: 13560-190, São Carlos, São Paulo, Brasil E-mail: may_barbieri@hotmail.com 